\title{
Development of a Bioaerosol single particle detector (BIO IN) for the Fast Ice Nucleus CHamber FINCH
}

\author{
U. Bundke ${ }^{1}$, B. Reimann ${ }^{1}$, B. Nillius ${ }^{1}$, R. Jaenicke ${ }^{2}$, and H. Bingemer ${ }^{1}$ \\ ${ }^{1}$ Institute for Atmospheric and Environmental Sciences, Goethe University, Frankfurt, Germany \\ ${ }^{2}$ Institute for Physics of the Atmosphere, Johannes Gutenberg-University, Mainz, Germany
}

Received: 10 September 2009 - Published in Atmos. Meas. Tech. Discuss.: 6 October 2009

Revised: 27 January 2010 - Accepted: 28 January 2010 - Published: 23 February 2010

\begin{abstract}
In this work we present the setup and first tests of our new BIO IN detector. This detector was constructed to classify atmospheric ice nuclei (IN) for their biological content. It is designed to be coupled to the Fast Ice $\mathrm{Nu}$ cleus $\mathrm{CHamber}$ FINCH. If one particle acts as an ice nucleus, it will be at least partly covered with ice at the end of the development section of the FINCH chamber. The device combines an auto-fluorescence detector and a circular depolarization detector for simultaneous detection of biological material and discrimination between water droplets, ice crystals and non activated large aerosol particles. The excitation of biological material with UV light and analysis of auto-fluorescence is a common principle used for flow cytometry, fluorescence microscopy, spectroscopy and imaging. The detection of auto-fluorescence of airborne single particles demands some more experimental effort. However, expensive commercial sensors are available for special purposes, e.g. size distribution measurements. But these sensors will not fit the specifications needed for the FINCH IN counter (e.g. high sample flow of up 10 LPM).

The newly developed -low cost- BIO IN sensor uses a single high-power UV LED for the electronic excitation instead of much more expensive UV lasers. Other key advantages of the new sensor are the low weight, compact size, and the little effect on the aerosol sample, which allows it to be coupled with other instruments for further analysis.

The instrument will be flown on one of the first missions of the new German research aircraft "HALO" (High Altitude and LOng range).
\end{abstract}

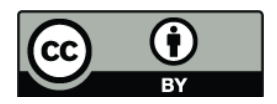

Correspondence to: U. Bundke (bundke@iau.uni-frankfurt.de)

\section{Introduction}

Ambient aerosol originates from multiple sources and consists of a wide variety of materials like mineral dust, sea salt, ammonium sulphate, acids, soot, organic polymers, plant debris, pollen, bacteria and spores. Several recent publications focus on the sources, distribution and potential impact of aerosol particles of biological origin on atmospheric processes like the formation of clouds and precipitation (Ariya and Amyot, 2004; Deguillaume et al., 2008; Georgakopoulos et al., 2009; Mohler et al., 2007; Mohler et al., 2008; Pratt et al., 2009; Prenni et al., 2009; Szyrmer and Zawadzki, 1997; Morris et al., 2008). Biological particles have the ability to act as cloud condensation nuclei $(\mathrm{CCN})$ and as ice nuclei (IN) and induce heterogeneous freezing even at high temperatures (Jaenicke, 2005; Jaenicke et al., 2007). Some biological material is known to be active as IN even at relatively high temperatures of up to $-2{ }^{\circ} \mathrm{C}$. They can be bacteria (e.g. pseudomonas syringae) (Vali and Schnell, 1975; Vali et al., 1976; Schnell and Vali, 1976; Maki and Garvey, 1975; Maki et al., 1974), pollen (von Blohn et al., 2005; Diehl et al., 2001; Diehl et al., 2002), fungal spores, etc. Secondary ice formation e.g. by mechanical fragmentation, splintering during riming of ice particles (Hallet-Mossop process) and fragmentation of large droplets during freezing will multiply the number of ice crystals in clouds by up to a factor of 10000 (Heymsfield and Mossop, 1984; Mossop, 1985; Pruppacher and Klett, 1996). Thus, even a small number of IN will have the potential to alter the microphysical structure of a cloud and play a key role in mid-latitude precipitation formation by the Bergeron-Findeisen process. We have designed the new BIO IN sensor to analyze the abundance of IN of biological origin.

Published by Copernicus Publications on behalf of the European Geosciences Union. 


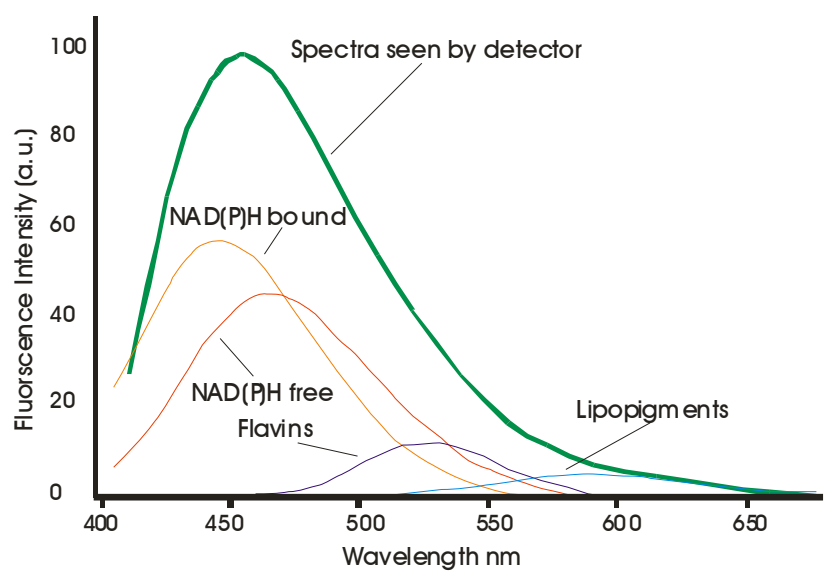

Fig. 1. Scheme of auto-fluorescence emission spectra of NADH, Flavins and Lipopigments. The sum of the different emission spectra in the 400-600 nm range will give the signal strength measured by the BIO IN detector. Figure modified from (Palumbo and Pratesi, 2004).

The interest in the detection of particles of biological origin in ambient aerosol has greatly increased during the last decade. A method to distinguish biological material from non-biological particles utilizes the detection of autofluorescence (intrinsic fluorescence) after irradiation with UV light (Seaver et al., 1999; Pan et al., 2009; Pan et al., 2003; Hairston et al., 1997). Ho (Ho et al., 2000) compared fluorescence measurements (UV-APS) to reference sampler data that provide culturable or living bio aerosol number concentrations. Biological matter consists of various different substances. Some of them are efficient fluorophores. For the excitation of auto-fluorescence of these substances, two UV excitation wavelength ranges are common: $260-280 \mathrm{~nm}$ and $340-380 \mathrm{~nm}$.

(a) Wavelength range $260-280 \mathrm{~nm}$

Protein fluorescence is induced by absorption of radiation in this wavelength range. The aromatic side-chains of the amino acids tryptophan, tyrosine and phenylalanine are primarily responsible for the inherent fluorescence of proteins. Tryptophan is the main fluorophore among them, since both its molar absorptivity and the fluorescence quantum yield are typically several times higher as compared to the other amino acids. Therefore absorption spectra of proteins often resemble the absorption of tryptophan, and their maxima are mostly located at about $275-280 \mathrm{~nm}$ (Wetlaufer, 1962). The corresponding protein fluorescence emission spectra vary with the protein-solvent environment and peaks are typically located in the region around $330-350 \mathrm{~nm}$ (Demchenko, 1986). Proteins are ubiquitous in all biological matter including not vegetative forms and cell fragments, which makes them to universal biomarkers. However we did not select this UV range for excitation because false counts caused by non-biological aromatic hydrocarbons (e.g. present in soot) will occur, leading to over-estimation of the number concentration of bioparticles.

b) Wavelength range $340-380 \mathrm{~nm}$

Apart from the proteins, there are several enzymatic co-factors present, which act as auto-fluorophores at longer absorption wavelengths, namely the reduced forms of the nicotinamide adenine dinucleotide (NADH (Coenzyme 1)) and derivatives (e.g. NADPH) and the flavins (e.g. Riboflavin (Vitamin B2), flavin adenine dinucleotide (FAD) see Fig. 1. Both classes of substances are involved in the metabolism of cells (citric acid cycle). The intermediates with the nicotinamide group in the reduced form (NADH, NADPH) are very efficient fluorophores, while their oxidized forms $\left(\mathrm{NAD}^{+}, \mathrm{NADP}^{+}\right)$are non-fluorescent. Therefore the fluorescence emission from vegetative cells is much higher than that from others with minimized metabolism, like bacterial spores. This makes the blue $\mathrm{NAD}(\mathrm{P}) \mathrm{H}$ fluorescence emission band (centered around $450 \mathrm{~nm}$ ) a marker for viability of cells (Hairston et al., 1997). However, this effect may be partly compensated by an increase of the FAD green fluorescence emission band (centred around $540 \mathrm{~nm}$ ), because the redox state of the FAD cofactors is in equilibrium to the mitochondrial $\mathrm{NAD}^{+} / \mathrm{NADH}$ pool, and the most efficient flavine fluorophores lipoamide dehydrogenase and electron transfer flavoprotein are highly fluorescent in their oxidized forms (Huang et al., 2002).

The UV LED in our BIO IN detector operates at $365 \mathrm{~nm}$, and the fluorescence wavelengths range from $400 \mathrm{~nm}$ to $600 \mathrm{~nm}$ collecting the emission from both NADH and flavins. We do not expect to be able to distinguish cells or fragments which show no or very low fluorescence, which might be caused by deterioration or ageing. When coupled to FINCH it might also be the case that a very small biological particle acts as IN and grows to detectable size, but its overall fluorescence is too small to be classified as biological. For these reasons it is clear that we will be able to detect only a lower limit of viable biological IN.

Although fluorescence from inorganic material like glass or kaolin cannot be excluded, fluorescence from these material is more than one order of magnitude weaker than that of biological material (Sivaprakasam et al., 2004) and is supposed to be negligible.

\section{Experimental setup}

The single particle fluorescence detector for the in situ measurement of biological ice nuclei is based on the optical detector of the Fast Ice Nucleus CHamber (FINCH), which has been previously described in detail (Bundke et al., 2008). 


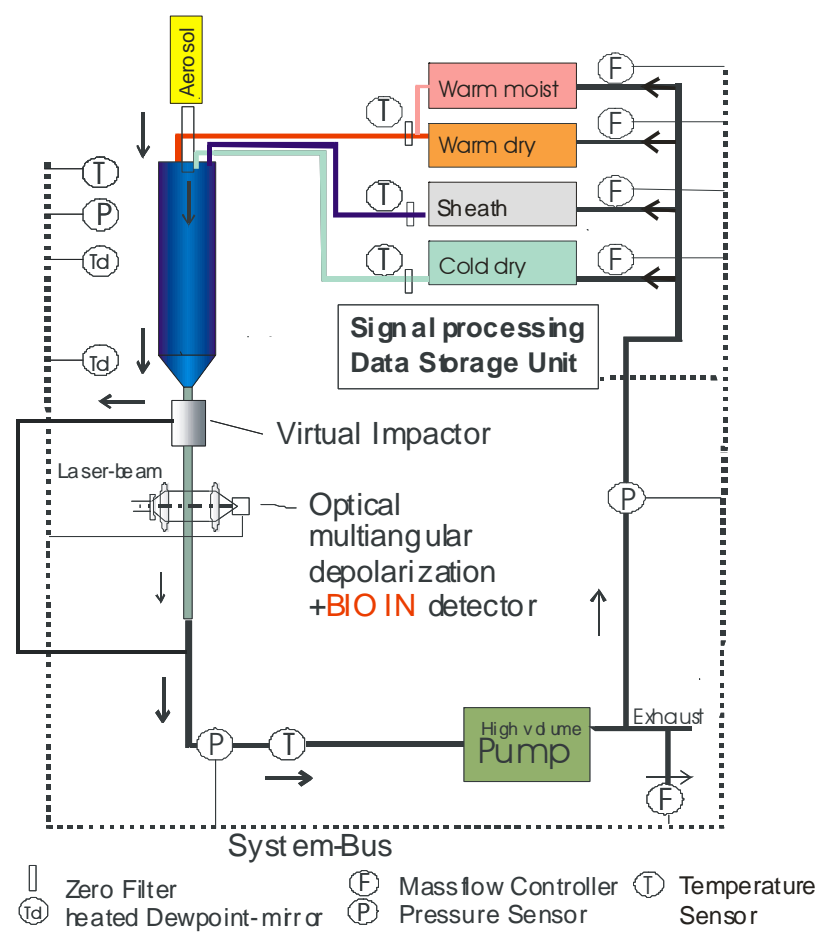

Fig. 2. Schematic flow diagram of the FINCH counter. The new $\mathrm{BIO}$ IN detector is incorporated in the depolarization detector located behind the virtual impactor at the bottom of the development section. Modified from (Bundke et al., 2008).

Briefly, in FINCH a sample flow of ambient aerosol is mixed with a warm and moist air flow as well as with a cold and dry flow in the mixing region of the instruments chamber, where IN particles are activated at well-defined freezing temperatures and supersaturations (see Fig. 2). The particles grow while flowing through the processing chamber of $1.35 \mathrm{~m}$ length. All ice particles pass a virtual impactor, which removes $90 \%$ of the gas flow, including non-activated aerosol particles and small water droplets. The optical detector, which discriminates water droplets from ice crystals, is mounted behind the outlet nozzle of the impactor. Here, the different depolarization behavior of water and ice with respect to scattered circular polarized light is used by analyzing the $P_{44} / P_{11}$ ratio of the scattering matrix. The collimated beam of a $30 \mathrm{~mW} 635 \mathrm{~nm} \mathrm{cw}$ (continuous wave) diode laser passes a circular polarizer and is mildly focused to an elliptical spot of $2.5 \times 1 \mathrm{~mm}$, which crosses the $2 \mathrm{~mm}$ diameter gas stream perpendicular (see Figs. 3 and 4). Light which is backscattered by droplets and ice crystals is collected in the range of $100^{\circ}$ up to $130^{\circ}$ scattering angle. After a condenser lens a quarter waveplate converts the circular polarized light back into linear polarized light, which is either $45^{\circ}$ or $135^{\circ}$ polarized from the principal axis, depending on the direction of circular polarization. A beam splitting cube separates the two components $P_{R C}$ and $P_{L C}$ of the linear polarized light.

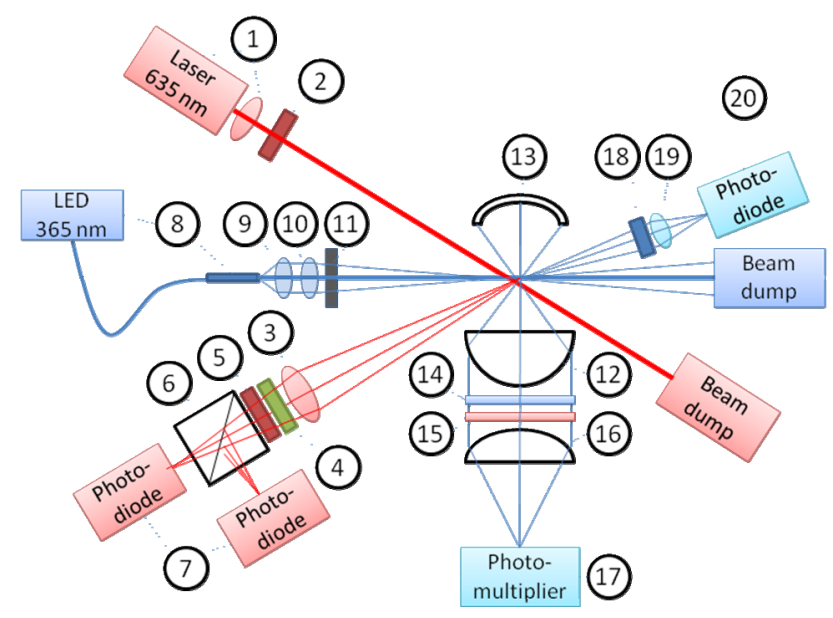

Fig. 3. Schematic diagram of the BIO IN detector optics. The numbered optical parts are given in Table 1. The aerosol flow intersects the paper plane vertically at the point of intersection of the laser and UV-LED beam (see also Fig. 4).

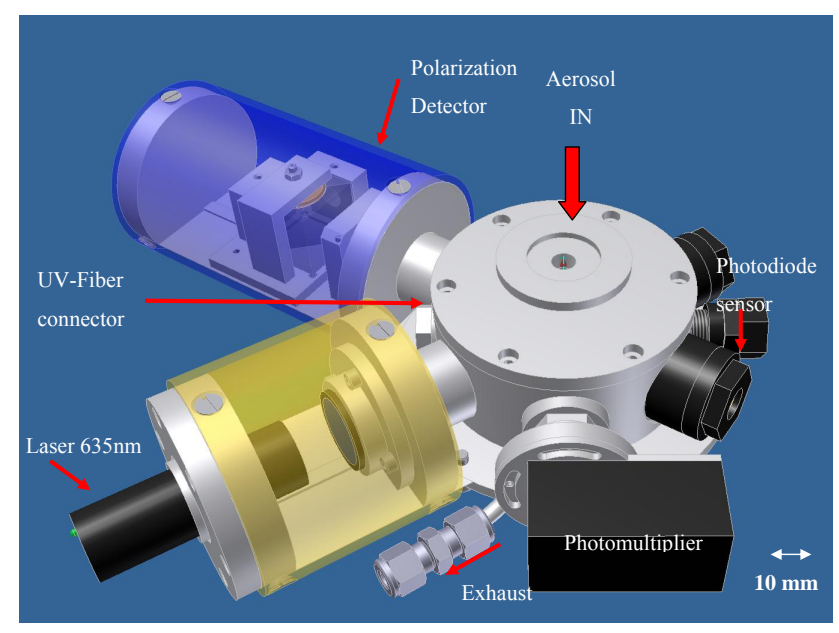

Fig. 4. Physical setup of the BIO-IN detector.

The signals $P_{R C}$ and $P_{L C}$ are detected separately with two photodiodes. It is possible to discriminate water droplets and ice crystals by determining the normalized $P_{44} / P_{11}$ ratio of the scattering matrix, which is given by Eq. (1) for this particular case (see Bundke et al., 2008 for details).

$P_{44} / P_{11}=\frac{P_{R C}-P_{L c}}{P_{R C}+P_{L C}}$

The only modification in this section of the detector is an additional $600 \mathrm{~nm}$ long-pass filter, which is placed between the quarter waveplate and the beam splitting cube in order to avoid miscounting by scattered UV and fluorescence light. We use the total scattered signal (sum of both channels $\left.P_{R C}+P_{L C}\right)$ as trigger for the fluorescence detection. 
Table 1. Physical setup of the BIO-IN detector(see also Fig. 3).

\begin{tabular}{|c|c|c|c|}
\hline & Part & Specification & Function \\
\hline & Aerosol inlet & $2 \mathrm{~mm}$ diameter & Gas flow approx. 6 LPM \\
\hline 1 & $\begin{array}{l}\text { Scattering Laser with Collimator, } \\
\text { Stocker Yale Inc., DLS Series }\end{array}$ & $\begin{array}{l}635 \mathrm{~nm}, 30 \mathrm{~mW} \text { output power [at } \\
\text { detection volume: elliptical spot } \\
2.5 \mathrm{~mm} \times 1.0 \mathrm{~mm} \text {, approx. } 15 \mathrm{~mW} \text { ] }\end{array}$ & Laser for depolarization scattering \\
\hline 2 & Circular polarizer & Polymer film, transmission approx. 50\% & $\begin{array}{l}\text { Changes linear laser polarization into } \\
\text { circular polarization }\end{array}$ \\
\hline 3 & Achromatic lens & $\mathrm{f} / \#=2$ approx. & $\begin{array}{l}\text { Collects scattered light and focuses it to } \\
\text { detector }\end{array}$ \\
\hline 4 & $\lambda / 4$ retarder & $\begin{array}{l}\text { Zero order quartz waveplate, } 633 \mathrm{~nm} \\
\text { design wavelength }\end{array}$ & $\begin{array}{l}\text { Changes circular polarized light into } \\
\text { parallel and perpendicular linear } \\
\text { polarized light }\end{array}$ \\
\hline 5 & long-pass filter $600 \mathrm{~nm}$ & $\begin{array}{l}\text { Transmission wavelength }>625 \mathrm{~nm} \text {, } \\
\text { rejection wavelength }<570 \mathrm{~nm}\end{array}$ & $\begin{array}{l}\text { Blocks scattered UV and most of } \\
\text { fluorescence light, transmits } 635 \mathrm{~nm} \\
\text { scattered light }\end{array}$ \\
\hline 6 & Polarizing beam splitting cube & $\begin{array}{l}\text { Transmission efficiency } T_{\mid}>95 \% \text {, } \\
\text { reflection efficiency } T_{\perp}>99.5 \%\end{array}$ & $\begin{array}{l}\text { Separates the light according to the } \\
\text { direction of polarization }\end{array}$ \\
\hline 7 & 2 silicon photodiodes & $\begin{array}{l}\text { VIS/NIR, max. sensitivity } 60 \mathrm{mV} / \mathrm{nW} \text {, in- } \\
\text { tegrated transimpedance amplifier }\end{array}$ & $\begin{array}{l}\text { Signal detection, trigger, } \\
\text { distinction between water and ice }\end{array}$ \\
\hline 8 & $\begin{array}{l}\text { UV-LED, Omicron Laserage, LED- } \\
\text { MOD365 }\end{array}$ & $\begin{array}{l}250 \mathrm{~mW} \text { LED output, fiber coupling, UV } \\
\text { Silica fiber, } 1000 \mu \mathrm{m} \text { core dia., } 1.5 \mathrm{~m} \\
\text { length, approx. } 90 \mathrm{~mW} \text { (end of the fiber) }\end{array}$ & UV source for fluorescence excitation \\
\hline 9 & Condensor lens & Aspheric, $\mathrm{f} / \#=0.9$ & Collimation of UV fiber output \\
\hline 10 & Focusing lens & $\begin{array}{l}\text { At detection volume: circular spot } \\
2.5 \times 2.5 \mathrm{~mm} \text {, approx. } 40 \mathrm{~mW}\end{array}$ & Focuses UV to detection volume \\
\hline 11 & Emission filter & $\begin{array}{l}\text { Narrow bandpass filter, } 360 \mathrm{~nm} \text { center } \\
\text { wavelength, max. transmission } 75 \% \text {, Full } \\
\text { width at half maximum } 10 \mathrm{~nm}\end{array}$ & $\begin{array}{l}\text { Blocks unwanted long-wavelength output } \\
\text { from LED }\end{array}$ \\
\hline 12 & Condensor lens & Aspheric, $\mathrm{f} / \#=0.8$ & Collects fluorescence light \\
\hline 13 & Reflector & Spherical mirror & Collects fluorescence light \\
\hline 14 & Long-pass filter $400 \mathrm{~nm}$ & $\begin{array}{l}\text { Transmission wavelength }>430 \mathrm{~nm} \text {, } \\
\text { rejection wavelength }<375 \mathrm{~nm}\end{array}$ & Blocks scattered UV light \\
\hline 15 & Short-pass filter $600 \mathrm{~nm}$ & $\begin{array}{l}\text { Transmission wavelength }<580 \mathrm{~nm} \text {, } \\
\text { rejection wavelength }>620 \mathrm{~nm}\end{array}$ & Blocks scattered $635 \mathrm{~nm}$ light \\
\hline 16 & Focusing lens & $\mathrm{f} / \#=1.5$ & Focuses light to photomultiplier \\
\hline 17 & $\begin{array}{l}\text { Photomultiplier, Hamamatsu } \\
\text { H9656-20 }\end{array}$ & $\begin{array}{l}\text { Photomultiplier tube module with low } \\
\text { noise amplifier }\end{array}$ & Signal detection fluorescent particles \\
\hline 18 & Condensor lens & $\mathrm{f} / \#=1,5$ & $\begin{array}{l}\text { Light collection for UV scattering } \\
\text { detection }\end{array}$ \\
\hline 19 & Short-pass filter $400 \mathrm{~nm}$ & $\begin{array}{l}\text { Transmission wavelength }<385 \mathrm{~nm} \text {, } \\
\text { rejection wavelength }>420 \mathrm{~nm}\end{array}$ & $\begin{array}{l}\text { Blocks fluorescence and scattered } 635 \mathrm{~nm} \\
\text { light }\end{array}$ \\
\hline 20 & Silicon photodiode & $\begin{array}{l}\text { VIS/NIR, max. sensitivity } 60 \mathrm{mV} / \mathrm{nW} \text {, } \\
\text { integrated transimpedance amplifier }\end{array}$ & $\begin{array}{l}\text { Signal detection for control of beam } \\
\text { alignment and LED power stability }\end{array}$ \\
\hline
\end{tabular}


The UV source used for the excitation of the bioaerosol particles is a fiber-coupled high-power LED with $250 \mathrm{~mW}$ output at $365 \mathrm{~nm}$, operating in $\mathrm{cw}$ mode. The UV light is focused by an aspheric two-lens collimating focusing assembly with $360 \mathrm{~nm}$ band-pass emission filter to a circular spot of about $2.5 \mathrm{~mm}$ diameter, which overlaps with both the $2 \mathrm{~mm}$ diameter cross section of the gas stream and the elliptical spot of the circular polarized $635 \mathrm{~nm}$ scattering laser (see Fig. 3).

The fluorescence light is collected perpendicular to the UV beam axis by an aspheric condenser lens and an additional spherical reflector. Two optical filters separate the fluorescence light from the scattered light of both light sources. After this a second lens focuses it to a photomultiplier detector. Additionally a photodiode sensor is mounted in the forward scattering direction $\left(35^{\circ} \pm 5^{\circ}\right)$ behind a $400 \mathrm{~nm}$ shortpass filter and a focusing lens. The signals obtained in this UV scattering channel are broader and less sensitive than that of the depolarization scattering channels. Therefore we use it mainly for coincidence measurement with the depolarization scattering channels to check the alignment of the beams. Additionaly the background signal can be used to monitor the intensity of the UV LED and normalize the signals to the LED Power.

The signals are sampled in parallel by using a NI PCI 6132 data acquisition module with up to $3 \mathrm{MS} / \mathrm{s}$ per channel and are analyzed by a peak detection algorithm using the LabVIEW data acquisition software (National Instruments Corporation, Austin (TX), USA). While particles are detected using the circular depolarization detector, bioaerosol particles are identified and counted, if the fluorescence signal extends a significant threshold value ( $5 \sigma$ of the noise, see example signal Fig. 6). The ratio of the number of bioaerosol particles to the total number of particles is calculated.

\section{Results}

In this section we describe the initial laboratory tests of the newly developed sensor with silica test particles as well as a first sampling of ambient aerosol.

\subsection{Initial laboratory tests}

Initial tests were performed on aerosol produced from a mixture of ca. $50 \%$ fluorescent $10 \mu \mathrm{m}$ spherical silica particles ("Fluo-Blue", Spherotech, Lake Forest (IL), USA) and 50\% non-fluorescent $10 \mu \mathrm{m}$ spherical particles ("Silica particles", Spherotech, USA) in water suspension. The fluorescent dye has its excitation maximum at $350-360 \mathrm{~nm}$, and the fluorescence emission wavelengths range from 400 to $560 \mathrm{~nm}$. Particles were suspended using a home-made atomizer and were dried by mixing with a dry carrier gas. The total gas flow was about 6 LPM (liter per minute), which is consistent with the flow rates of FINCH after the development chamber and virtual impactor in normal operation mode. For the ini-

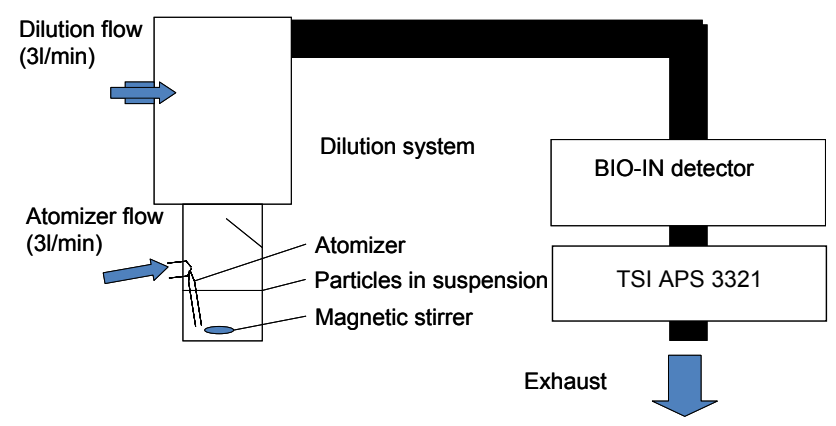

Fig. 5. Schematic diagram of the test-aerosol suspension unit (silica micro-particles, see text for details).

tial tests the detector was decoupled from FINCH, because silica particles are hardly IN active (See Fig. 5 for details of the setup).

Figure 6 shows a signal graph of two particles passing the detector within one second. Here the photomultiplier was operated with a lower gain. The first (smaller) particle shows a significant fluorescence signal and the second particle almost no fluorescence signal.

In general the scattering intensities of the test particles were found to be relatively broadly distributed in the frequency of occurrence histogram. The two histograms in Figs. 7 and 8 show the particle numbers in relation to their scattering and fluorescence intensities, respectively. The relatively broad distribution in Fig. 7 is a little surprising on the first look. However, a check of the aerosol size distribution using an aerodynamic particle sizer (APS, TSI Inc. type 3321) showed that our test aerosol was not monodisperse. The size distribution in front of the detector was found to be similarly broad, with its maximum at about $8.5 \mu \mathrm{m}$ and a small secondary maximum at $13 \mu \mathrm{m}$. This is consistent with the specifications of the distributor of the test particles (not monodisperse, average size of the particles $10 \mu \mathrm{m}$ ).

The distribution of the fluorescence intensity seen in the related histogram was similarly broad, which can be explained with both the broad size distribution and the different dye concentrations in the silica particles. Fig. 9 shows a scatter plot of the fluorescence intensity versus total scattering intensity based on single particle analysis. As can be easily seen, there is no clear separation between fluorescing and not fluorescing particles. The separation line drawn at 0.003 is based on an analysis of the noise level (see also Fig. 6 captions). Moreover no correlation between scattering intensity (which is proportional to the square of the particle size) and fluorescence intensity (proportional to the amount of dye) is evident. However in this particular run shown here, 546 of the 916 particles detected emitted fluorescence, which is equivalent to $60 \%$ of the particles and reproducibly seen during our lab tests with a $50 \% / 50 \%$ mixture of the fluorescing/non-fluorescing samples. Within the large errors of the mixing ratio resulting from uncertainties of 

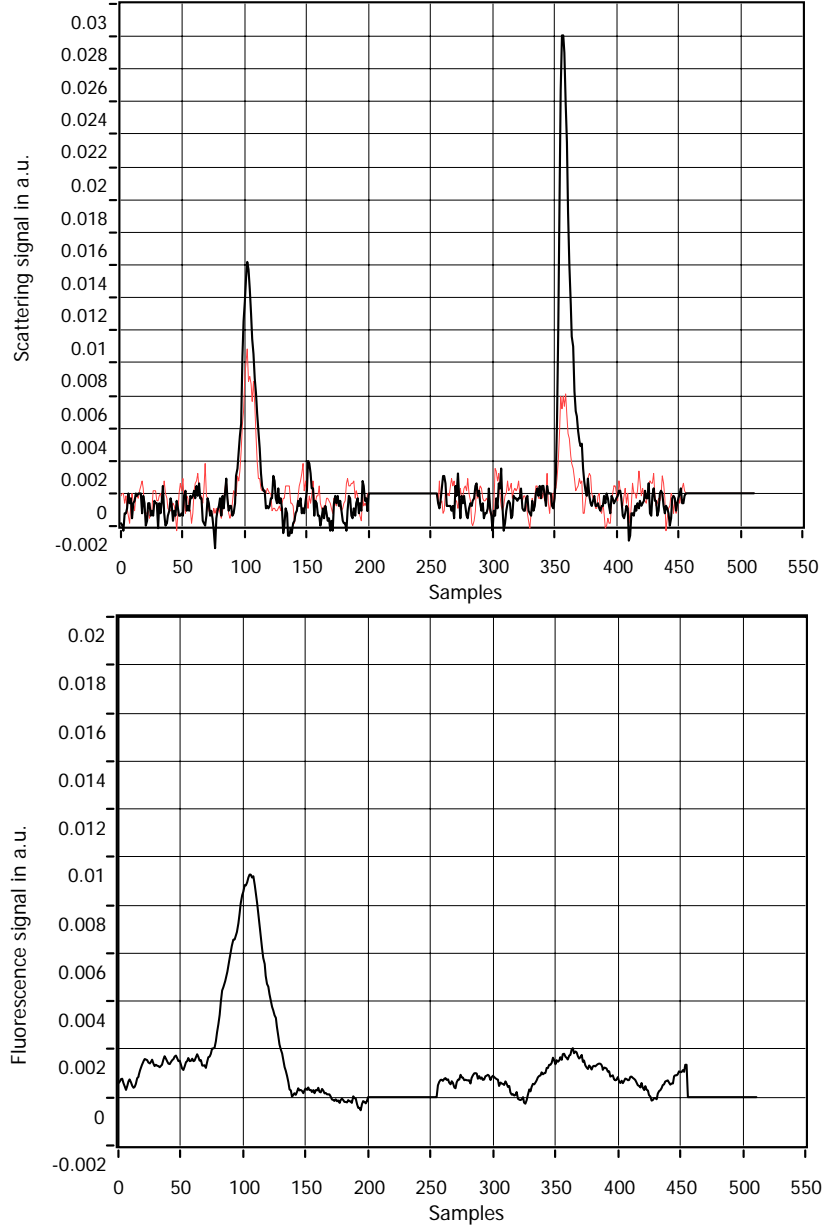

Fig. 6. Example of signal graphs of two test particles that have passed the detector within one second. On the y-axis the signal intensity and on the $\mathrm{x}$-axis the sample number taken at $200 \mathrm{kHz}$ are shown. The signal was triggered, thus peaks are centered at sample number 100. If more than one particle was detected the signal was added with a gap of 56 samples in advance. The upper panel shows the phase discriminating depolarization channels $\left(P_{R C}\right.$ red line and $P_{L C}$ black line), the lower the flourescence channel. For all signals displayed the constant background is substracted. Particles are counted as fluorescent if the signal maximum is larger than the photomultiplier background signal plus $5 \sigma_{\text {noise. }}$. For this measurement $\sigma_{\text {noise }}$ is 0.0006 which corresponds to a detection limit of 0.003 . In this example the first particle shows a significant but weak flourescence signal. The second particle shows no or only extremely weak fluorescence and is therefore counted as not fluorescent. The signals in the fluorescence channel are generally broader than the photodiode signals because the circular spot size of the UV source is larger than the elliptical spot of the diode laser. Thus the particles need more time to travel through the detection volume.

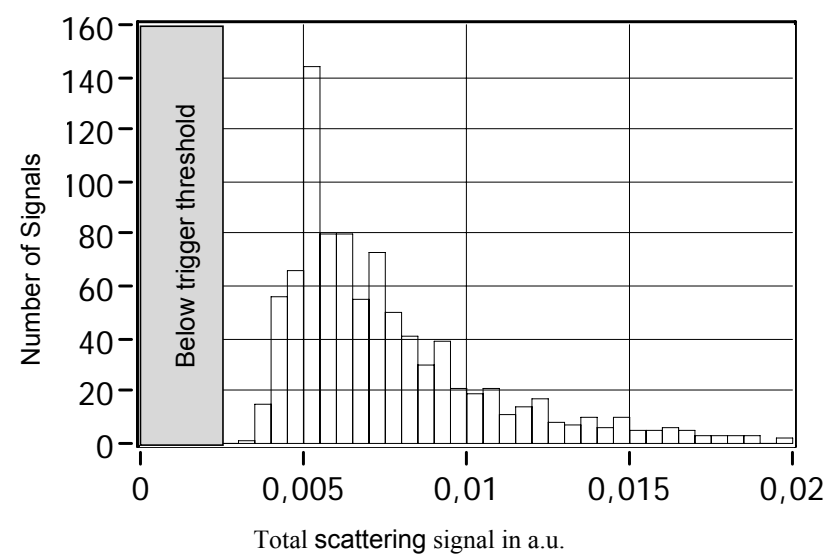

Fig. 7. Intensity histogram of the frequency of occurrence of the signal strength of the circular depolarization detector using test aerosol.

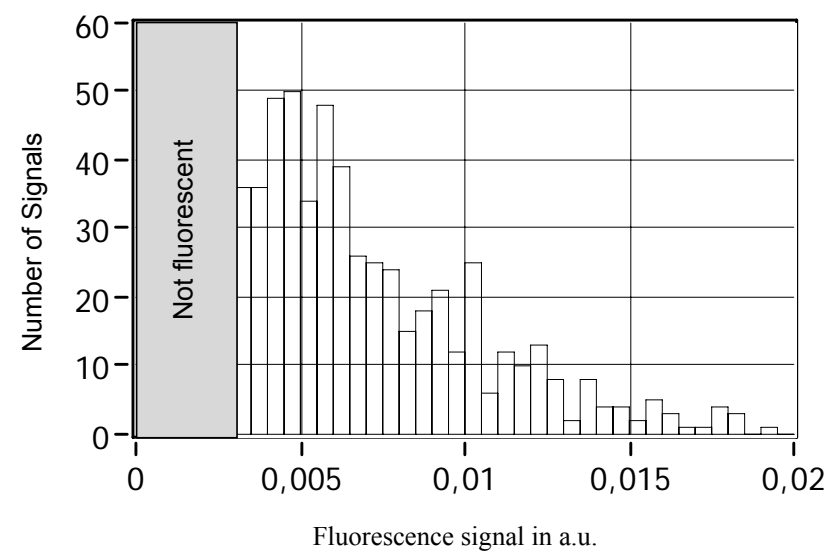

Fig. 8. Intensity histogram of the frequency of occurrence of the signal strength of the fluorescence detector using test aerosol.

the concentrations of the two sample solutions, the observed ratio of fluorescent particles to all particles is consistent with the mixing ratio.

\subsection{Initial tests with ambient aerosol}

Ambient aerosol was sampled directly through a $3 \mathrm{~m} \times 6 \mathrm{~mm}$ I.D. copper tube from the outside of the Geosciences Department building in Frankfurt am Main, Campus Riedberg, Germany, at $10 \mathrm{~m}$ above ground level on 26 June 2009, 14:3016:10. The sample flow rate was 5 LPM. In this example for atmospheric measurements, a total number of 704 particles have been counted, which amounts 7 particles per minute. 52 particles $(6.3 \%)$ have been found to be clearly fluorescent and therefore of biological origin. A nine minute ambient sample taken with the APS directly after the measurements resulted in a total number of 69 particles larger than $3 \mu \mathrm{m}$. If one assumes that the particle concentration and 


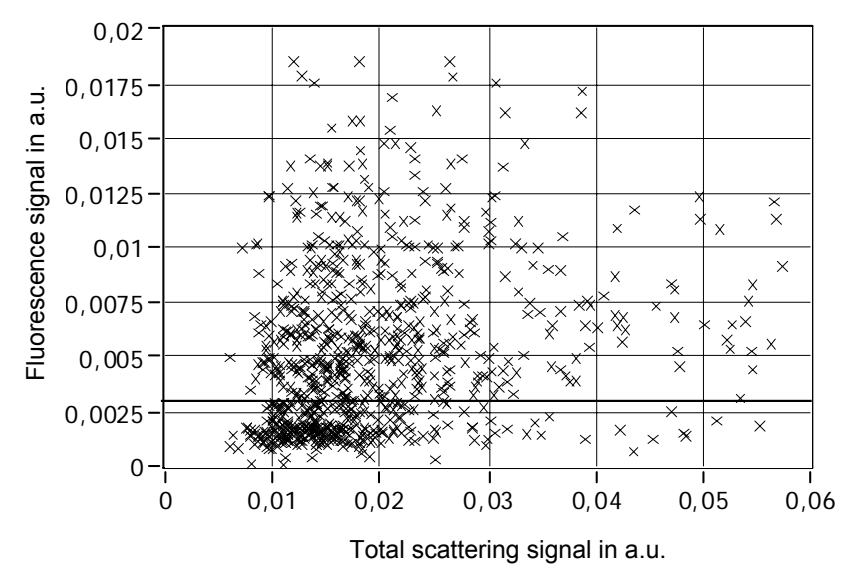

Fig. 9. Scatter plot of the fluorescence signal versus the total scattering signal intensity (sum of both polarization signals) on the basis of single particle analysis of the $10 \mu \mathrm{m}$ test particles. The line at 0.003 indicates the discrimination between fluorescent and not or only very low fluorescent particles.

size distribution did not vary significantly during the time of both measurements, then we may conclude from the total counts/minute that the detector triggered on particles larger than about $3 \mu \mathrm{m}$.

This observed biological fraction of particles $>3 \mu \mathrm{m}$ is a reasonable result for this initial test. It is consistent with the $75 \%$ quartile range of $1.7-5.5 \%$ based on 5 min samples for fluorescent biological particles $>1 \mu \mathrm{m}$ measured with a UVAPS (TSI Inc.) during a 4 month period (3 August-4 December 2006) at Mainz (Germany)(Huffman et al., 2009). Mainz is located located close to Frankfurt in the metropolitan area named "Rhein-Main region".

Figure 10 shows an example of a relatively small particle, for which the scattering intensity is only slightly above the triggering threshold, but which shows a strong fluorescence signal.

Figure 11 shows a scatter plot of the signal intensities in the scattering and the fluorescence channels. No correlation between particle size (proportional to the square root of the scattering intensity) and fluorescence intensity is observed. This is not surprising, given the large variance of biological particles in the atmosphere and the different concentrations of auto-fluorescent metabolites among them.

Up to now, no investigations about the influence of ice coverage on the fluorescence properties of the particles have been made. Ice coverage of the particles might have some influence on the detection probabilities, which we can hardly quantify yet, but they should be mentioned in the following. Certainly small biological IN which grow to detectable size can be miscounted as not fluorescing, because the overall amount of fluorophore metabolites is too small to be detected. For the ice cover itself we do not expect a large influence, because the transmission of a $10 \mu \mathrm{m}$ layer of ice is
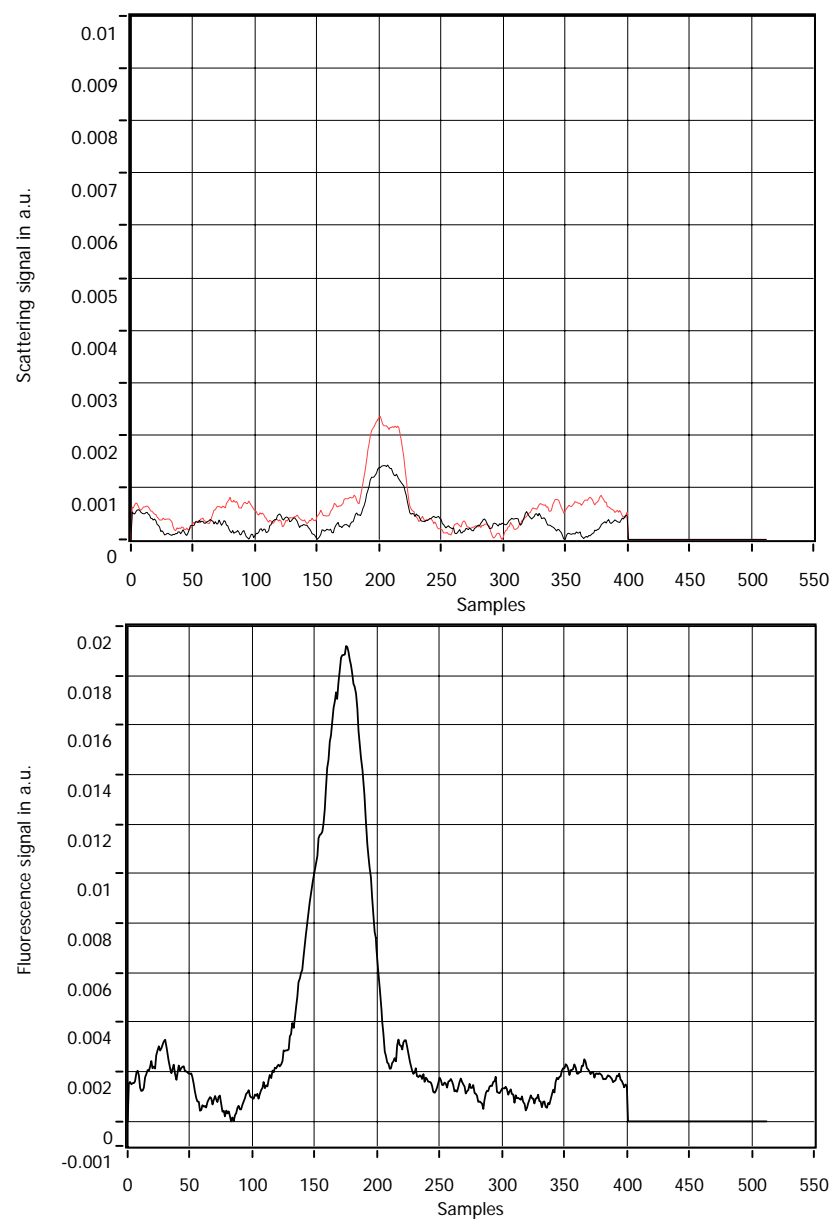

Fig. 10. Example of signal graphs where one small ambient particle have passed the detector. On the y-axis the signal in arbitrary units and on the $\mathrm{x}$-axis the sample number taken at $200 \mathrm{kHz}$ are shown. The signal was triggered, thus peaks are centered at sample number 200. The upper panel shows the phase discriminating depolarization chanel, the lower panel shows the fluorescence channel. In this case a small particle (weak scattering signal) exhibits a strong fluorescence signal. Here it is obvious that particle size is not directly correlated to the fluorescence signal (see also Fig. 8). The small shift of the signal maxima of about 25 samples $(=125 \mu \mathrm{s})$ between the two channels originates from a small misalignment of the two beams.

larger than $99.999 \%$ in the wavelength region from near UV to VIS (Wozniak and Dera, 2007; Warren, 1984). A second point is the loss of UV irradiation on particle by reflection at the ice surface, which can roughly be estimated to be $1-4 \%$ (depending on angle and surface structure). The fluorescence emission on the other hand is omni-directional, thus scattering inside the ice shell can be neglected. The fluorescence intensity at low temperatures might be even higher compared to the same particles measured at room temperature, because of an increased fluorescence quantum yield at lower temperature. Generally most fluorophores show temperature dependent fluorescence quenching, with higher fluorescence 


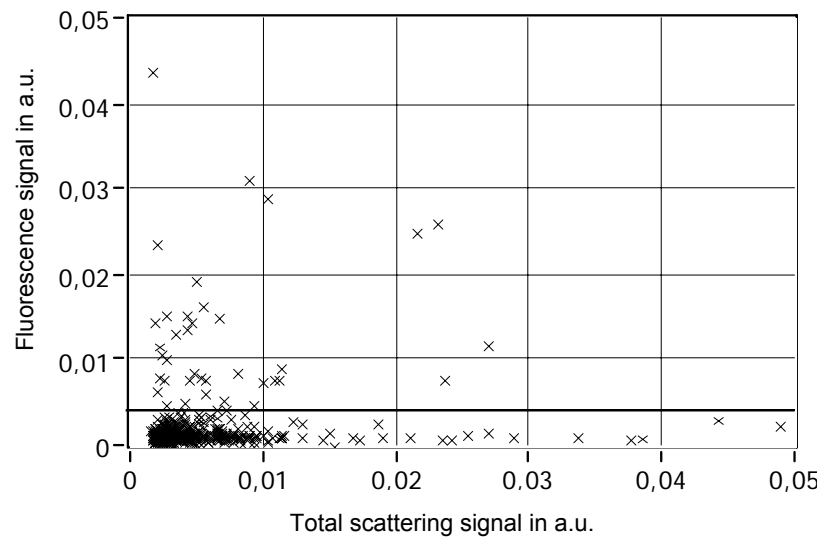

Fig. 11. Scatter plot of the fluorescence signal versus the total scattering signal intensity (sum of both polarization signals) on the basis of single particle analysis. The line at 0.004 indicates the discrimination between fluorescent and non or only very low fluorescent particles. There is no significant correlation between particle size (scattering intensity) and fluorescence signal strength.

lifetimes and emission quantum yield at low temperatures. The same behavior was found for NADH (Scott et al., 1969). Summing up we expect that the detection probability will not be reduced significantly by the ice shell.

\section{Conclusions}

It is known that some aerosol particles which contain biological material activate as IN at relatively high temperatures. They will thus activate first during cloud icing and will determine the temperature of the onset of cloud icing, and may alter the microphysical structure of the cloud significantly. The new BIO IN detector allows to classify IN for their biological content and hopefully constitutes an helpful contribution for the understanding of the origin of IN.

The performance of this low-cost detector is better than we expected originally but is still limited because of the signal to noise ratio. Thus, the separation between biological and non-biological material is not sharp for particles with low fluorescence activity (e.g. spores). The fluorescence yield is related to the concentrations of NADH/NADPH and Flavoproteins (FAM, FAD, Riboflavin, etc.), which depend also on their oxidation state, varying with the energy metabolism of the living cells. During our initial tests we identified at least $6 \%$ of particles larger than $3 \mu \mathrm{m}$ to be of biological origin.

\section{Outlook}

It is planned to enhance the signal to noise ratio by using a a powerful $355 \mathrm{~nm}$ solid state Laser, equivalent to the one used by the UV-APS of TSI company (Hairston et al., 1997). It may be possible then to differentiate various types of biolog- ical particles such as spores, pollen, bacteria, cell fragments, by use of a high speed spectrometer to obtain the dispersed fluorescence spectrum, instead of the simple photomultiplier. This will improve the design significantly - but not longer at low cost.

Another possible improvement is the use of photomultipliers in the scattering channels instead of the less sensitive photodiodes. By this we expect to shift the detection limit to particle sizes smaller one $\mu \mathrm{m}$.

Furthermore we would like to make some comparison experiment with the commercial UV-APS. It is clear that our detector is less sensitive than the UV-APS, especially for the detection of small particles. But we expect a similar detection efficiency for fluorescent bio-particles.

The BIO IN detector as part of the FINCH measurement system is currently in the certification process for use onboard the new HALO aircraft.

Acknowledgements. We thank Ulrich Pöschl for intensive discussions and suggestions and for providing the 4 Month period UV-APS time series at Mainz. This work has been performed within Project A1 of the Collaborative Research Centre (SFB) 641 "The Tropospheric Ice Phase", funded by the German Science Foundation and by the Grant Bu 1432/3-1 (Development of an ice nucleus (IN) counter for HALO) within the framework of SPP 1294: Atmospheric and Earth system research with the "High Altitude and Long Range Research Aircraft" and by the virtual institute Aerosol Cloud Interaction VI233 funded by the Helmholtz society.

Edited by: M. Wendisch

\section{References}

Ariya, P. A. and Amyot, M.: New Directions: The role of bioaerosols in atmospheric chemistry and physics, Atmos. Environ., 38, 1231-1232, 2004.

Bundke, U., Nillius, B., Jaenicke, R., Wetter, T., Klein, H., and Bingemer, H.: The fast Ice Nucleus chamber FINCH, Atmos. Res., 90, 180-186, 2008.

Deguillaume, L., Leriche, M., Amato, P., Ariya, P. A., Delort, A.M., Pöschl, U., Chaumerliac, N., Bauer, H., Flossmann, A. I., and Morris, C. E.: Microbiology and atmospheric processes: chemical interactions of primary biological aerosols, Biogeosciences, 5, 1073-1084, 2008, http://www.biogeosciences.net/5/1073/2008/.

Demchenko, A. P.: Ultraviolet spectroscopy of proteins, Springer, Berlin ; London, 312 pp., 1986.

Diehl, K., Quick, C., Matthias-Maser, S., Mitra, S. K., and Jaenicke, R.: The ice nucleating ability of pollen - Part I: Laboratory studies in deposition and condensation freezing modes, Atmos. Res., 58, 75-87, 2001.

Diehl, K., Matthias-Maser, S., Jaenicke, R., and Mitra, S. K.: The ice nucleating ability of pollen: Part II. Laboratory studies in immersion and contact freezing modes, Atmos. Res., 61, 125133, 2002.

Georgakopoulos, D. G., Desprs, V., Fröhlich-Nowoisky, J., Psenner, R., Ariya, P. A., Pösfai, M., Ahern, H. E., Moffett, B. F., and 
Hill, T. C. J.: Microbiology and atmospheric processes: biological, physical and chemical characterization of aerosol particles, Biogeosciences, 6, 721-737, 2009, http://www.biogeosciences.net/6/721/2009/.

Hairston, P. P., Ho, J., and Quant, F. R.: Design of an instrument for real-time detection of bioaerosols using simultaneous measurement of particle aerodynamic size and intrinsic fluorescence, J. Aerosol Sci., 28, 471-482, 1997.

Heymsfield, A. J. and Mossop, S. C.: Temperature-Dependence of Secondary Ice Crystal Production during Soft Hail Growth by Riming, Q. J. Roy. Meteor. Soc., 110, 765-770, 1984.

Ho, J., Spence, M., and Hairston, P.: Measurement of biological aerosol with a fluorescent aerodynamic particle sizer (FLAPS): Correlation of optical data with biological data, Rapid Methods for Analysis of Biological Materials in the Environment, 30, 177-201, 2000.

Huang, S. H., Heikal, A. A., and Webb, W. W.: Two-photon fluorescence spectroscopy and microscopy of $\mathrm{NAD}(\mathrm{P}) \mathrm{H}$ and flavoprotein, Biophys. J., 82, 2811-2825, 2002.

Huffman, J. A., Treutlein, B., and Pöschl, U.: Fluorescent biological aerosol particle concentrations and size distributions measured with an ultraviolet aerodynamic particle sizer (UV-APS) in Central Europe, Atmos. Chem. Phys. Discuss., 9, 17705-17751, 2009,

http://www.atmos-chem-phys-discuss.net/9/17705/2009/.

Jaenicke, R.: Abundance of cellular material and proteins in the atmosphere, Science, 308, 73-73, 2005.

Jaenicke, R., Matthias-Maser, S., and Gruber, S.: Omnipresence of biological material in the atmosphere, Environ. Chem., 4, $217-$ 220, 2007.

Maki, L. R., Galyan, E. L., Changchi. M., and Caldwell, D. R.: Ice Nucleation Induced by Pseudomonas-Syringae, Appl. Microbiol., 28, 456-459, 1974.

Maki, L. R. and Garvey, D. M.: Bacterially Induced Ice Nucleation, Transactions-American Geophysical Union, 56, 994-994, 1975.

Möhler, O., DeMott, P. J., Vali, G., and Levin, Z.: Microbiology and atmospheric processes: the role of biological particles in cloud physics, Biogeosciences, 4, 1059-1071, 2007,

http://www.biogeosciences.net/4/1059/2007/.

Möhler, O., Georgakopoulos, D. G., Morris, C. E., Benz, S., Ebert, V., Hunsmann, S., Saathoff, H., Schnaiter, M., and Wagner, R.: Heterogeneous ice nucleation activity of bacteria: new laboratory experiments at simulated cloud conditions, Biogeosciences, 5, 1425-1435, 2008,

http://www.biogeosciences.net/5/1425/2008/.

Morris, C. E., Sands, D. C., Bardin, M., Jaenicke, R., Vogel, B., Leyronas, C., Ariya, P. A., and Psenner, R.: Microbiology and atmospheric processes: an upcoming era of research on biometeorology, Biogeosciences Discuss., 5, 191-212, 2008, http://www.biogeosciences-discuss.net/5/191/2008/.

Mossop, S. C.: Secondary Ice Particle-Production during Rime Growth - the Effect of Drop Size Distribution and Rimer Velocity, Q. J. Roy. Meteor. Soc., 111, 1113-1124, 1985.
Palumbo, G. and Pratesi, R.: Lasers and current optical techniques in biology, Royal Society of Chemistry, Cambridge, XXIV, 658 pp., 2004.

Pan, Y. L., Hartings, J., Pinnick, R. G., Hill, S. C., Halverson, J., and Chang, R. K.: Single-particle fluorescence spectrometer for ambient aerosols, Aerosol Sci. Technol., 37, 628-639, 2003.

Pan, Y. L., Pinnick, R. G., Hill, S. C., and Chang, R. K.: ParticleFluorescence Spectrometer for Real-Time Single-Particle Measurements of Atmospheric Organic Carbon and Biological Aerosol, Environ. Sci. Technol., 43, 429-434, 2009.

Pratt, K. A., DeMott, P. J., French, J. R., Wang, Z., Westphal, D. L., Heymsfield, A. J., Twohy, C. H., Prenni, A. J., and Prather, K. A.: In situ detection of biological particles in cloud ice-crystals, Nature Geosci., 2, 397-400, 2009.

Prenni, A. J., Petters, M. D., Kreidenweis, S. M., Heald, C. L., Martin, S. T., Artaxo, P., Garland, R. M., Wollny, A. G., and Pöschl, U.: Relative roles of biogenic emissions and Saharan dust as ice nuclei in the Amazon basin, Nature Geosci., 2, 401-404, 2009.

Pruppacher, H. R. and Klett, J. D.: Microphysics of clouds and precipitation, 2nd rev. and enl. ed., Atmospheric and oceanographic sciences library; v. 18, Kluwer Academic Publishers, Boston, xx, 954 pp., 1996.

Schnell, R. C., and Vali, G.: Biogenic Ice Nuclei .1. Terrestrial and Marine Sources, J Atmos Sci, 33, 1554-1564, 1976.

Scott, T. G., Spencer, R. D., Leonard, N. J., and Weber, G.: Emission Properties of Nadh . Fluorescence Lifetimes and Quantum Efficiencies of Nadh and Simplified Synthetic Models, Abstr. Pap. Am. Chem. S., Bi39-\&, 1969.

Seaver, M., Eversole, J. D., Hardgrove, J. J., Cary, W. K., and Roselle, D. C.: Size and fluorescence measurements for field detection of biological aerosols, Aerosol Sci. Technol., 30, 174$185,1999$.

Sivaprakasam, V., Huston, A. L., Scotto, C., and Eversole, J. D.: Multiple UV wavelength excitation and fluorescence of bioaerosols, Opt. Express, 12, 4457-4466, 2004.

Szyrmer, W. and Zawadzki, I.: Biogenic and anthropogenic sources of ice-forming nuclei: A review, B. Am. Meteorol. Soc., 78, 209_ 228, 1997.

Vali, G. and Schnell, R. C.: Biogenic Sources of Atmospheric Ice Nuclei - Review, Transactions-American Geophysical Union, 56, 994-994, 1975.

Vali, G., Christensen, M., Fresh, R. W., Galyan, E. L., Maki, L. R., and Schnell, R. C.: Biogenic Ice Nuclei .2. Bacterial Sources, J. Atmos. Sci., 33, 1565-1570, 1976.

von Blohn, N., Mitra, S. K., Diehl, K., and Borrmann, S.: The ice nucleating ability of pollen: Part III: New laboratory studies in immersion and contact freezing modes including more pollen types, Atmos. Res., 78, 182-189, 2005.

Warren, S. G.: Optical-Constants of Ice from the Ultraviolet to the Microwave, Appl. Optics, 23, 1206-1225, 1984.

Wetlaufer, D. B.: Ultraviolet Spectra of Proteins and Amino Acids, Advances in Protein Chemistry, 17, 303-390, 1962.

Wozniak, B. and Dera, J.: Light absorption in sea water, Atmospheric and oceanographic sciences library; v. 33, Springer, New York, N.Y., viii, 452 p., 458 p. of plates pp., 2007. 